ISSN $1392-1215 \longrightarrow$ ELEKTRONIKA IR ELEKTROTECHNIKA

2011. No. 7(113)

\author{
ELECTRICAL ENGINEERING
}

$T 190$

ELEKTROS INŽINERIJA

\title{
Research on Operating Performance for Hybrid Rotor Synchronous Motor
}

\section{Xuezhen Chen}

College of Electrical \&Electronic Engineering, Huazhong University of Science and Technology, Room 6107, Dianjilou, Luoyu road,1037\#, Wuhan, P.R. China, phone:+862787542626,e-mail: cxz4688@163.com Department of Electrical \&Electronic Engineering, Huangshi Institute of Technology, Huangshi, P.R. China

\section{Chenglin Gu}

College of Electrical \&Electronic Engineering, Huazhong University of Science and Technology, Room 6107, Dianjilou, Luoyu road, 1037\#, Wuhan, P.R. China

crossref $\mathrm{http} / / / \mathrm{dx}$.doi.org/10.5755/j01.eee.113.7.603

\section{Introduction}

The high-density axially-laminated anisotropic (ALA) rotor with axial laminations interleaved with insulation spacer is capable of yielding a comparatively higher saliency ratio. The machine employs the stator of an induction motor. In the course of the startup experiments, once the frequency of the VVVF inverter was beyond a critical value, the inverter-fed prototype presented oscillation and asynchronous operation [1]. Permanent magnet synchronous motor (PMSM) has high power density, high power factor and high efficiency. The better operating performance can be obtained by hybrid ALA rotor and PMSM rotor [2, 3]. The two-pole combined rotor motor was designed in [4], and experiment results showed that the performance with the open-loop variable frequency operating was improved. The hybrid rotor motor has advantages of above two motors, whose rotors do not have damping winding. Instability can still occur with the open-loop $V / f$ control. The influence on the stability of the reluctance machine due to the change in machine parameters was researched by using small signal displacements in $[5,6]$. The influence on step response of stepping machine due to the changes of viscous damping torque coefficient and inertia of damper was researched by scholars [7]. So far, it is reported that the hybrid rotor motor is still relatively rare in the literatures.

This paper describes the causes of the oscillation on four-pole hybrid rotor motor and ALA rotor motor with the open loop $V / f$ control by using small signal model. The relationships between the fraction length $k$ of the surface permanent magnet (SPM) part and electromagnet damping coefficient were presented, and the influence on stability and maximum load capability with inertial damper on rotor shaft due to the change of $k$ value, the fraction length of SPM part, the damping coefficient $T_{d d}$ and the inertial $J_{d}$ of the damper was discussed. Fig. 1 is the cross-section of the four-pole hybrid rotor, and Fig. 2 is the virtual prototype of the four-pole hybrid rotor.

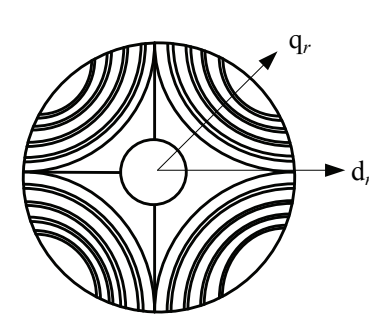

a)

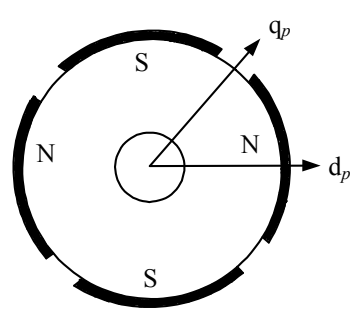

b)
Fig. 1. Cross-section of four-pole ALA-SPM rotor: a - ALA part; b-SPM part

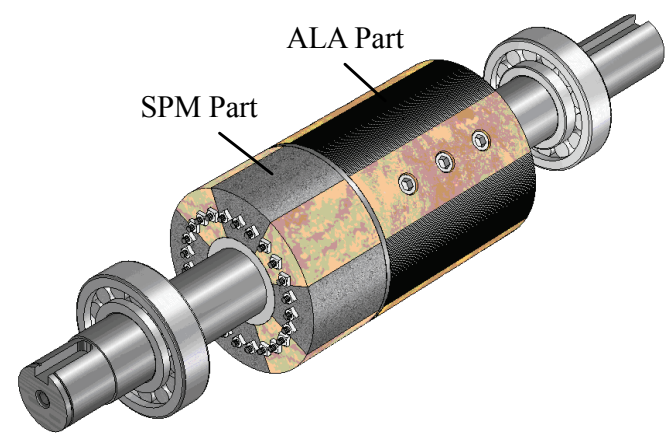

Fig. 2. Four-pole ALA-SPM rotor

\section{Small signal model}

For the simple calculation and analysis, 1) saturation ignored, 2) SPM part isotropic $\left(L_{d p}=L_{q p}=L_{p}\right)$, 3) Influence on leakage magnetic flux ignored. The phasor diagram of ALA-SPM rotor motor in d-q frame is illustrated in Fig. 3. 


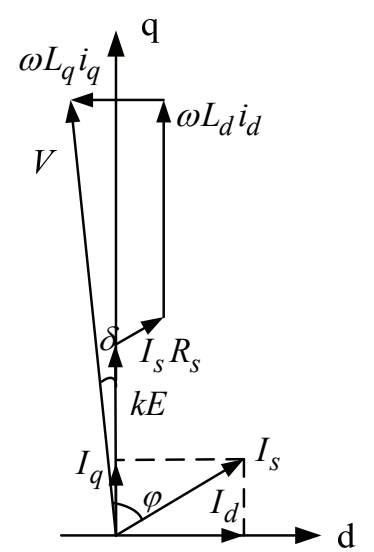

Fig. 3. Phasor diagram of ALA-SPM rotor motor

Due to the symmetric structure, the steady-state equations are established as follows:

$$
\left\{\begin{array}{c}
-V \sin \delta=I_{d} R_{s}-\omega L_{q} I_{q}, \\
V \cos \delta=I_{q} R_{s}+\omega L_{d} I_{d}+k E,
\end{array}\right.
$$

where $V$ is the amplitude of fundamental component of the phase voltage, $I_{s}$ is the amplitude of fundamental component of the phase current, $0 \leq k \leq 1 \quad(k=0$ is the complete ALA rotor motor, $0<k<1$ is hybrid rotor motor, $k=1$ is the complete SPM rotor motor), $E$ is the back-EMF amplitude of SPM rotor motor, $\delta$ is the angle between the voltage $V$ and $E, L_{d}$ is the direct axis equivalent inductance and $L_{q}$ is the quadrature axis equivalent inductance, expressions are given as:

$$
\left\{\begin{array}{l}
L_{d}=k L_{p}+(1-k) L_{d r} \\
L_{q}=k L_{p}+(1-k) L_{q r}
\end{array}\right.
$$

where $L_{d r}$ and $L_{q r}$ is the direct axis inductance and the quadrature axis of ALA motor respectively.

In general, synchronous oscillation and asynchronous oscillation can occur in the open-loop startup process. Amplitude of synchronous oscillation gradually decreases and finally reaches a new equilibrium point. Amplitude of asynchronous oscillation continuously grows and finally leads to desynchronizing. Suppose the tiny vibration of the rotor displacement is sinusoidal, $\Delta \theta$ is given by

$$
\Delta \theta=\Delta \theta_{m} \sin \alpha t
$$

where $\Delta \theta_{m}$ is the amplitude of the vibration and $\alpha$ is the oscillating frequency.

Rotor position angle $\theta$ given by

$$
\theta=\theta_{0}+\omega_{r 0} t+\Delta \theta
$$

where all the symbols with subscript " 0 " represent the variables in steady state.

Consequently, rotor speed is given by

$$
\omega_{r}=\frac{d \theta}{d t}=\omega_{r 0}+\Delta \omega_{r}
$$

The voltage equation can be rewritten as follows:

$$
\left\{\begin{array}{c}
-V \sin \left(\omega_{1} t-\theta\right)=R i_{d}-L_{q} i_{q} \omega_{r}+L_{d} \frac{d i_{d}}{d t}, \\
V \cos \left(\omega_{1} t-\theta\right)=R i_{q}+L_{d} i_{d} \omega_{r}++k \psi_{f} \omega_{r}+L_{q} \frac{d i_{q}}{d t} .
\end{array}\right.
$$

The stator currents are:

$$
\left\{\begin{array}{l}
i_{d}=i_{d 0}+\Delta i_{d}, \\
i_{q}=i_{q 0}+\Delta i_{q} .
\end{array}\right.
$$

Substituting (3)-(6) and (8) to (7), the tiny vibration of the current with sinusoidal steady state $\Delta i_{d}$ and $\Delta i_{q}$ is obtained as:

$$
\left\{\begin{array}{l}
\dot{\Delta} I_{d}=\left(\Delta I_{d}+j \Delta I_{d}^{\prime}\right) \Delta \theta, \\
\dot{\Delta} I_{q}=\left(\Delta I_{q}+j \Delta I_{q}^{\prime}\right) \Delta \theta .
\end{array}\right.
$$

By applying the similar method, the electromagnetic torque can also be disturbed as

$$
T_{e}=1.5 p\left[k \psi_{f} i_{q}+\left(L_{d}-L_{q}\right) i_{d} i_{q}\right]=T_{e 0}+\Delta T_{e},
$$

where $\Delta T_{e}$ is the ripple torque, obtained

$$
\begin{aligned}
\Delta T_{e} & =1.5 p\left[k \psi_{m}\left(\cos \theta \Delta i_{q}-\Delta \theta \sin \theta i_{q 0}\right)+\right. \\
& \left.+\left(L_{d}-L_{q}\right) i_{d 0} \Delta i_{q}+i_{q 0} \Delta i_{d}\right] .
\end{aligned}
$$

Again, omitting the higher order components, $\Delta T_{e}$ can be simplified as

$$
\Delta T_{e}=k_{s} \Delta \theta-k_{d} \Delta \omega_{r}
$$

where $k_{s}$ is the synchronizing torque coefficient, $k_{d}$ is the electromagnetic damping torque coefficient.

\section{Damping torque coefficient}

The similar approach can also be iterated to disturb the rotor motion equation

$$
\frac{J}{p} \frac{d^{2} \theta}{d t^{2}}+k_{B} \frac{d \theta}{d t}+T_{L}=T_{e}
$$

yielding

$$
\begin{aligned}
& \frac{J}{p} \frac{d^{2} \theta}{d t^{2}}+\left(k_{B}+k_{d}\right) \frac{d \Delta \theta}{d t}+k_{s} \Delta \theta+ \\
+ & k_{B} \omega_{r 0}+T_{L}=T_{e 0}+\Delta T_{L} .
\end{aligned}
$$

Substituting $\Delta \theta$ from (3) and $\Delta T_{e}$ from (10) into (12), dynamic instability equations can be obtained as:

$$
\begin{gathered}
k_{B} \omega_{r 0}+T_{L}-T_{e 0}=0, \\
k_{B}+k_{d}=0, \\
J \alpha^{2}+p k_{s}=0 .
\end{gathered}
$$

As seen, the systematic damping coefficient is combined with the mechanical damping coefficient $k_{B}$ and the electromagnetic damping torque coefficient $k_{d}$. The system can be stable if $k_{B}+k_{d}>0$, and the system can be instable if $k_{B}+k_{d} \leq 0$ [8]. The electromagnetic damping 
torque coefficient $k_{d}$ can be derived from equations (6), (8), (13) and (15) when the frequency is given a value.

The main parameters in the four-pole hybrid prototype are $L_{q \mathrm{r}}=0.031 \mathrm{H}, L_{d \mathrm{r}}=0.2 \mathrm{H}, L_{p}=0.03819 \mathrm{H}$, $\psi_{\mathrm{f}}=0.4232 \mathrm{H}, J=0.0267 \mathrm{~kg} \cdot \mathrm{m}^{2}, p=2$. As we can see in Fig. 4 , due to the absence of starting cage, and with the frequency increasing, $k_{d}$ is changing from positive to negative minimum value, then there is a rising trend. The stability of the motor improves as $k$ is increased. But negative electromagnet damping coefficient can still occur, and consequently the exotic disturbance can lead to self-excited oscillation.

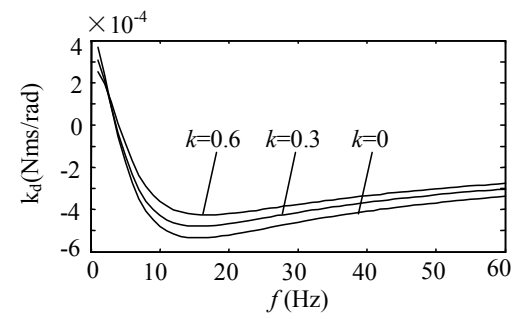

Fig. 4. Electromagnet damper coefficient $k_{d}$ versus frequency $f$ under no-load

\section{Operating performance}

From above analysis, the total damping coefficient of the system can be negative. It is suggested that a mechanical damper should be added on rotor shaft to increase system damping coefficient. This paper presents the relationship between the viscous damping coefficient $T_{d d}$, inertial $J_{d}$ of the mechanical damper and the operating performance of the different rotor motor under load.

The small signal dynamic model of the rotor with mechanical damper on the rotor shaft is derived as:

$$
\begin{gathered}
\frac{d \Delta \omega_{r}}{d t}=\frac{p}{J} \Delta T_{e}-\frac{B}{J} \Delta \omega_{r}-\frac{p}{J} \Delta T_{L}+\frac{p}{J} \Delta T_{d}, \\
\Delta T_{d}=-T_{d d}\left(\Delta \omega_{r}-\Delta \omega_{d}\right), \\
\frac{d \Delta \omega_{d}}{d t}=-\frac{\Delta T_{d}}{J_{d}},
\end{gathered}
$$

where $T_{d}$ is the friction damping torque, $J_{d}$ is inertial and $\omega_{d}$ is the angular speed of the damping flywheel.

The simplified small signal dynamic model with inertial damper on rotor shaft can be obtained from a simplified linearized model of the hybrid rotor motor. The model in block diagram form is shown in Fig. 5, and the dotted line part is the dynamic model without inertial damper.

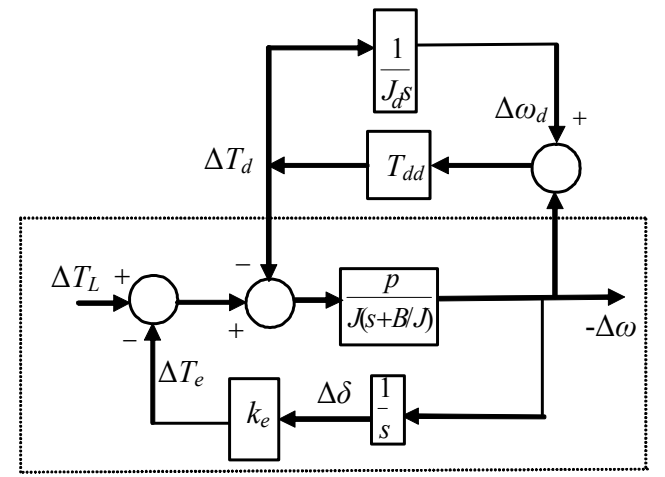

Fig. 5. Block diagram of the small signal dynamic mode with damper

The parameter $k_{e}$ is the electromechanical spring constant, which is equal to the slope of the load-angle torque curve of the motor at the steady state operating point [9], i.e.

$$
k_{e}=\frac{\partial T_{e}}{\partial \delta} \mid \delta_{0}
$$

The transfer function can be obtained from Fig. 5, and the expression is given by

$$
G(s)=\frac{p\left(J_{d} s+T_{d d}\right) s}{a_{0} s^{3}+a_{1} s^{2}+a_{2} s+a_{3}},
$$

where $\quad a_{0}=J J_{d}, \quad a_{1}=J_{d} B+J T_{d d}+J_{d} T_{d d} p \quad$, $a_{2}=T_{d d} B+p k_{e} J_{d}, a_{3}=p k_{e} T_{d d}$.

It can be seen from equation (20) that the systematic pole and zero point can be ascertained by $J_{d}$ and $T_{d d}$ values, and this reveals that the location of the motor rotor poles in $s$ plane can be controlled by adjusting inertial damper.

The dynamic equations of the current $i_{d}, i_{q}$ and load angle $\delta$ are given by:

$$
\begin{gathered}
\frac{d i_{d}}{d t}=-\frac{R}{L_{d}} i_{d}+\frac{L_{q}}{L_{d}} i_{q} \omega_{r}-\frac{V}{L_{d}} \sin \delta, \\
\frac{d i_{q}}{d t}=-\frac{R}{L_{q}} i_{q}-\frac{L_{d}}{L_{q}} i_{d} \omega_{r}-\frac{k \psi_{f}}{L_{q}} \omega_{r}+\frac{V}{L_{q}} \cos \delta, \\
\frac{d \delta}{d t}=\omega_{s}-\omega_{r} .
\end{gathered}
$$

From above (16) (18) and (21) (23), small signal linearized state equations with mechanical inertial damper are derived as

$$
\left[\begin{array}{l}
\dot{\Delta} i_{d} \\
\dot{\Delta} i_{q} \\
\dot{\Delta} \delta \\
\dot{\Delta} \omega_{r} \\
\dot{\Delta} \omega_{d}
\end{array}\right]=\left[\begin{array}{ccccc}
-\frac{R}{L_{d}} & \frac{L_{q}}{L_{d}} \omega_{r 0} & -\frac{V}{L_{d}} \cos \delta_{0} & \frac{L_{q}}{L_{d}} i_{q 0} & 0 \\
-\frac{L_{d}}{L_{q}} \omega_{r 0} & -\frac{R}{L_{q}} & -\frac{V}{L_{q}} \sin \delta_{0} & -\left(\frac{L_{d}}{L_{q}} i_{d 0}+\frac{k \psi_{f}}{L_{q}}\right) & 0 \\
0 & 0 & 0 & -1 & 0 \\
\frac{3 p^{2}}{2 J}\left(L_{d}-L_{q}\right) i_{q 0} & \frac{3 p^{2}}{2 J}\left[\left(L_{d}-L_{q}\right) i_{d 0}+k \psi_{f}\right] & 0 & -\left(\frac{B}{J}+\frac{T_{d d}}{J}\right) & \frac{T_{d d}}{J} \\
0 & 0 & 0 & \frac{T_{d d}}{J_{d}} & -\frac{T_{d d}}{J_{d}}
\end{array}\right]\left[\begin{array}{c}
\Delta i_{d} \\
\Delta i_{q} \\
\Delta \delta \\
\Delta \omega_{r} \\
\Delta \omega_{d}
\end{array}\right]+\left[\begin{array}{c}
0 \\
0 \\
0 \\
-\frac{p}{J} \\
0
\end{array}\right] .
$$


Equation (24) can be considered as a vector system of differential equation of the form

$$
\Delta \dot{x}=A(x) \Delta x+B(x) \Delta u,
$$

where $\Delta \boldsymbol{x}$ is the perturbations matrix for the state variable $\boldsymbol{x}$ $\boldsymbol{A}(\boldsymbol{x})$ is the state transition matrix, $\Delta \boldsymbol{u}$ is the input perturbation matrix, and $\boldsymbol{B}(\boldsymbol{x})$ is the input matrix.

According to the linear system stability theory, the system is stable under the given operating condition if the real part of the $\boldsymbol{A}(\boldsymbol{x})$ eigenvalues are all negative. This paper presents operating performance at the rate frequency $50 \mathrm{~Hz}$, which is most important for the synchronous motor near synchronous speed, with mechanical damper under different load conditions.

In the paper, the commercial software "MATLAB" is used in the small signal model. It can be seen from Fig. 6 that ALA rotor motor in the entire load range is instable, and however, the combined rotor motor at $k=0.6$ in the load torque range $\left(15.6 \mathrm{~N} \cdot \mathrm{m} \leq T_{L} \leq 33.2 \mathrm{~N} \cdot \mathrm{m}\right)$ is stable. Obviously, the load capability and operating performance of the hybrid rotor motor are improved. The reasonable $k$ value should consider the comprehensive performance of the hybrid motor [10, 11]. In Fig. 7, ALA rotor motor in the load torque range $\left(1 \mathrm{~N} \cdot \mathrm{m} \leq T_{L} \leq 19.2 \mathrm{~N} \cdot \mathrm{m}\right)$ and the hybrid rotor motor in the load torque range $\left(1 \mathrm{~N} \cdot \mathrm{m} \leq T_{L} \leq 33.2 \mathrm{~N} \cdot \mathrm{m}\right)$ are all stable, and it can be seen from Fig. 7 that the reasonable $T_{d d}$ can improve the stability of the motor. In Fig. 8, the stability of the system is reduced if $J_{d}$ is too small, and the dynamic performance becomes inferior if $J_{d}$ is too big, hence the reasonable $J_{d}$ can improve the stability and the dynamic performance.

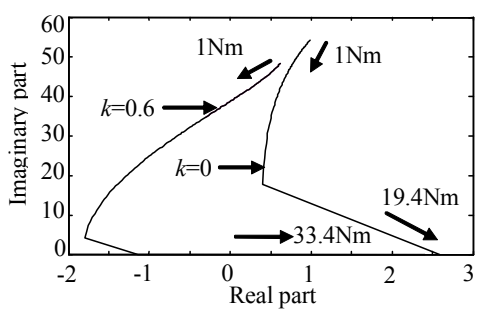

Fig. 6. Loci of the $A(x)$ dominant eigenvalues under different load conditions, with the different $k$ (without inertial damper)

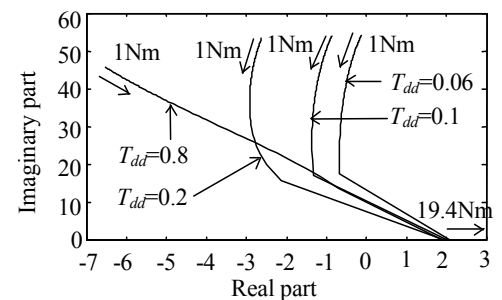

(a)

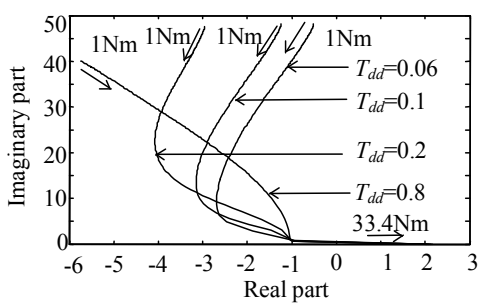

(b)

Fig. 7. Loci of the $A(x)$ dominant eigenvalues under different load conditions, with different $T_{d d}$, at $J_{d}=0.02$ ((a) $k=0$, (b) $k=0.6$ )

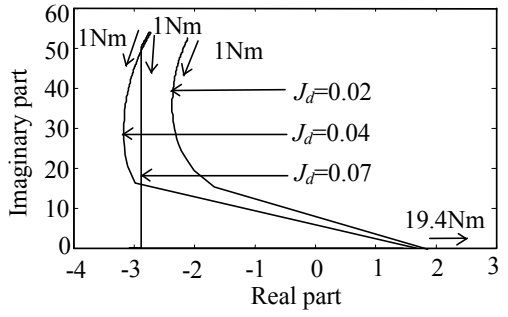

(a)

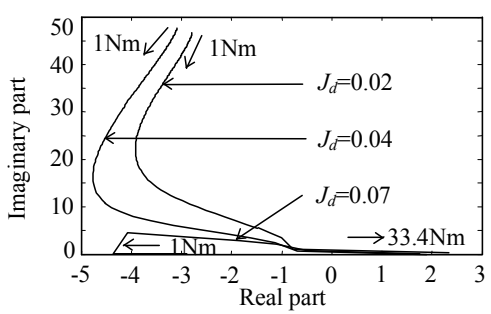

(b)

Fig. 8. Loci of the $A(x)$ dominant eigenvalues under different load conditions, with different $J_{d}$, at $T_{d d}=0.06$ ((a) $k=0$, (b) $k=0.6$ )

\section{Experiments}

First, experiments of the open-loop startup performance on the two-pole ALA rotor motor and hybrid rotor motor under no-load conditions are implemented by a VVVF inverter (Pasasonic MIX374BS) supply, and the inverter has start/stop and acceleration/deceleration functions. Table 1 and table 2 show the data of the two-pole ALA rotor motor and hybrid rotor motor under variable frequency no-load start respectively. It can be seen from table1 that the startup performance of ALA rotor motor is remarkably improved with the mechanical inertial damper on the rotor shaft. Compared the data shown in table1 with those in table2, the performance of hybrid rotor motor is better than complete ALA motor. Fig. 9 shows the rotor speed of the two-pole complete ALA rotor motor, and the motor with mechanical inertial damper can ultimately keep synchronous with the power frequency and reach the rated speed. Fig. 10 shows the rotor speed of the two-pole hybrid rotor motor with damper under no-load. Obviously, the performance of the hybrid motor is improved, which is consistent with the theoretical analysis.

Table 1. Data of the two-pole ALA rotor motor under variable frequency no-load start

\begin{tabular}{|c|c|c|}
\hline \multicolumn{3}{|c|}{ without damper } \\
\hline $\boldsymbol{f}\left(\boldsymbol{H}_{\boldsymbol{z}}\right)$ & $\boldsymbol{n}(\mathbf{r} / \mathbf{m i n})$ & $\boldsymbol{I}_{\boldsymbol{u}}(\mathbf{A})$ \\
\hline 10 & 602 & 1.6 \\
\hline 13 & $784-787$ & $1.9-2.1$ \\
\hline 15 & $906-910$ & $2.5-2.7$ \\
\hline 17 & $1024-1033$ & $2.9-3.2$ \\
\hline 19 & $1146-1154$ & $3.8-4.1$ \\
\hline 21 & $1255-1280$ & $4.2-4.9$ \\
\hline 23 & $1382-1400$ & $5.6-7.1$ \\
\hline 25 & - & OV \\
\hline 35 & - & - \\
\hline 45 & - & - \\
\hline 50 & - & - \\
\hline
\end{tabular}

\begin{tabular}{|c|c|c|}
\hline \multicolumn{3}{|c|}{ with damper } \\
\hline $\boldsymbol{f} / \mathbf{H z}$ & $\boldsymbol{n}(\mathbf{r} / \mathbf{m i n})$ & $\boldsymbol{I}_{\boldsymbol{u}}(\mathbf{A})$ \\
\hline 10 & 602 & 1.9 \\
\hline 13 & 783 & $2.1-2.3$ \\
\hline 15 & $901-905$ & $2.4-2.6$ \\
\hline 17 & $1026-1030$ & $2.8-2.9$ \\
\hline 19 & $1141-1147$ & $2.9-3.1$ \\
\hline 21 & $1269-1274$ & $3.1-3.6$ \\
\hline 23 & $1384-1387$ & $3.6-3.9$ \\
\hline 25 & $1503-1511$ & $3.9-4.2$ \\
\hline 35 & $2104-2113$ & $4.8-5.2$ \\
\hline 45 & $2702-2706$ & $3.1-3.6$ \\
\hline 50 & $3013-3014$ & 1.9 \\
\hline
\end{tabular}


Table 2. Data of the two-pole hybrid rotor motor under variable frequency no-load start

\begin{tabular}{|c|c|c|}
\hline \multicolumn{3}{|c|}{ without damper } \\
\hline $\boldsymbol{f}(\boldsymbol{H z})$ & $\boldsymbol{n}(\mathbf{r} / \mathbf{m i n})$ & $\boldsymbol{I}_{\boldsymbol{u}}(\mathbf{A})$ \\
\hline 5 & 300 & 4.4 \\
\hline 10 & 600 & 2.2 \\
\hline 15 & 902 & $2.8-3.0$ \\
\hline 20 & $198-1202$ & $4.8-5.1$ \\
\hline 30 & $1796-1811$ & $6.4-6.8$ \\
\hline 40 & $2414-2420$ & $3.5-3.7$ \\
\hline 50 & $3013-3014$ & 2.4 \\
\hline
\end{tabular}

\begin{tabular}{|c|c|c|}
\hline \multicolumn{3}{|c|}{ with damper } \\
\hline $\boldsymbol{f ( H z )}$ & $\boldsymbol{n}(\mathbf{r} / \mathbf{m i n})$ & $\boldsymbol{I}_{\boldsymbol{u}}(\mathbf{A})$ \\
\hline 5 & 300 & 4.4 \\
\hline 10 & 602 & 2.4 \\
\hline 15 & 907 & 2.3 \\
\hline 20 & 1207 & 2.4 \\
\hline 30 & 1812 & 2.2 \\
\hline 40 & 2410 & 2.2 \\
\hline 50 & 3013 & 2.3 \\
\hline
\end{tabular}

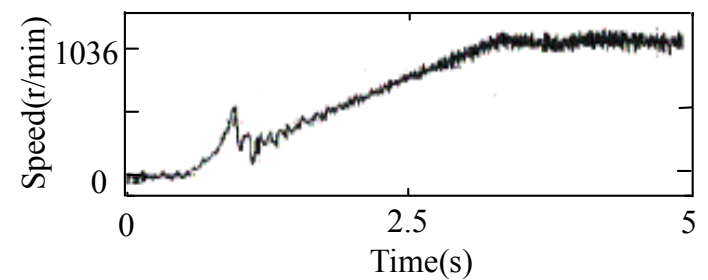

(a)

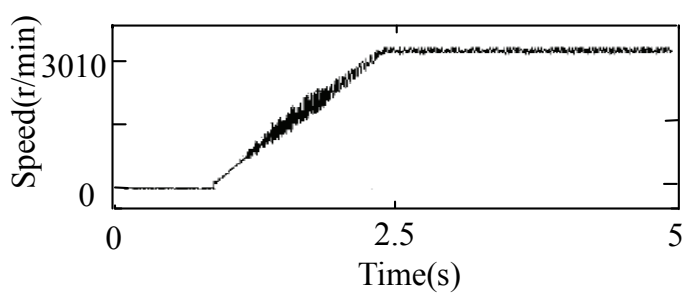

(b)

Fig. 9. Rotor speed of the two-pole complete ALA motor under no-load ((a) without damper (b) with damper)

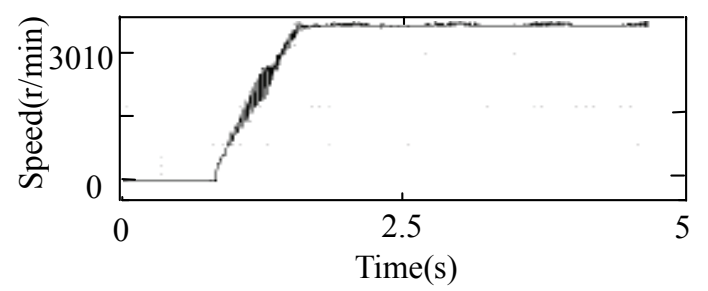

Fig. 10. Rotor speed of the two-pole hybrid rotor motor with damper

Then, the load experiment of four-pole ALA rotor motor is implemented under low speeds condition because the motor can not reach the rate synchronous speed without inertial damper by using inverter-fed source. Therefore, the load performance under the rate synchronous speed condition can be derived from the low speeds experiment results. The motor with inertial damper can obtain precisely load experiment results and runs very smoothly under the rate synchronous speed condition. Table 3 is data comparisons of the load performance without/with inertial damper. In table3, maximum desynchronizing torques are presented except for the $T_{e}$ value in the last column with inertial damper, the $T_{e}$ value without inertial damper in the last column is obtained through deduction. It shows that the output torque is significantly improved with inertial damper. However, the maximum desynchronizing torque can not be obtained due to over-current. The load value under the rate speed can be further increased if there is a larger capacity inverter.

Table 3. Data comparison of the load performance on without inertial damper and with inertial damper of four-pole ALA rotor motor

\begin{tabular}{|c|c|c|}
\hline \multicolumn{3}{|c|}{ without damper } \\
\hline $\begin{array}{c}\text { Phase } \\
\text { voltage(V) }\end{array}$ & $\begin{array}{c}\boldsymbol{n} \\
(\mathbf{r} / \mathbf{m i n})\end{array}$ & $\begin{array}{c}\boldsymbol{T}_{\boldsymbol{e}} \\
(\mathbf{N} \cdot \mathbf{m})\end{array}$ \\
\hline 132 & 900 & 3.55 \\
\hline 146 & 1050 & 3.86 \\
\hline 168 & 1200 & 4.55 \\
\hline 210 & 1500 & 6.56 \\
\hline
\end{tabular}

\begin{tabular}{|c|c|c|}
\hline \multicolumn{3}{|c|}{ with damper } \\
\hline $\begin{array}{c}\text { Phase } \\
\text { voltage( } \boldsymbol{V})\end{array}$ & $\begin{array}{c}\boldsymbol{n} \\
(\mathbf{r} / \mathbf{m i n})\end{array}$ & $\begin{array}{c}\boldsymbol{T}_{\boldsymbol{e}} \\
(\mathbf{N} \cdot \mathbf{m})\end{array}$ \\
\hline 132 & 904 & 9.3 \\
\hline 146 & 1054 & 9.56 \\
\hline 168 & 1205 & 11.02 \\
\hline 210 & 1504 & 12.95 \\
\hline
\end{tabular}

The rotor speed of the four-pole ALA rotor motor with damper under no-load is measured. Compared the Fig. 11 with the Fig. 9, the performance of the four-pole ALA motor is better than that of the two-pole ALA motor. This is reasonable because the four-pole motor has a relative low saliency ratio and the higher damping torque coefficient $k_{d}$.

Because the experimental research platform of four-pole hybrid rotor motor is still under construction, the more complete results, analysis and conclusion will be shown in the future.

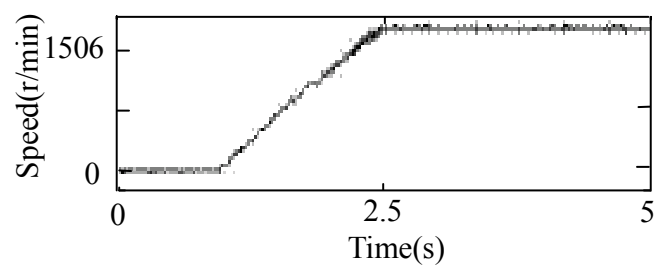

Fig. 11. Rotor speed of the four-pole ALA rotor motor with damper

\section{Conclusions}

This paper presents that the negative total damping coefficient of the system can cause oscillation in ALA rotor motor and the hybrid rotor motor. Increasing $k$, the stability and the maximum load capability of the stable state can be improved. By mounting an additional mechanical damper with proper $J_{d}$ and $T_{d d}$ on the rotor shaft, the experiment results show that the systematic damping coefficient can be increased, the robustness and anti-disturbance capability can be reinforced, the load performance can be improved.

\section{Acknowledgements}

Key Project Supported by Innovation Team of Huangshi Institute of Technology.

\section{References}

1. Gu C.L., Yi M.J. Study of Oscillation and Asynchronous Operation on ALA Rotor Motor // Proceedings of the CSEE, 2000. - Vol. 20. - No. 12. - P. 7-10.

2. Shigeo M., Masayuki S. Yoji T. Performance of PM-Assisted Synchronous Reluctance Motor for HighEfficiency and Wide Constant-Power Operation // IEEE Transactions on Industry Applications, 2001. - Vol. 37. - No. 5. - P. 1234-1239.

3. Boldea I., Lucian T., Cristian I. P. PM-Assisted Reluctance 
Synchronous Motor/Generator (PM-RSM) for Mild Hybrid Vehicles: Electro-magnetic Design // IEEE Transactions on Industry Applications, 2004. - Vol. 40. - P. 492-498.

4. Gu C. L., Chalmers B. J., Lu C. W. Rotor design optimization of synchronous machine with two-part rotor // IEEE International Electric Machines and Drives Conf, 1997. - P. 1-3.

5. Honsinger V. B. Steady State Performance of Reluctance Machine // IEEE Transactions on Power Apparatus and Systems, 1971. - P. 305-311.

6. Zhu J. H., Gu C. L. Experimental Research on Operating Performance of ALA Rotor Motor Driven by VVVF Inverter // Small \& Special Electrical Machines, 2007. - Vol. 35. P. 1-3.

7. Lawrenson P. J., Kingham I. E. Viscously coupled inertial damping of stepping motor // Proceedings IEE, 1975. - Vol.
122. - P. 1137-1140.

8. GU Aiyu, Lu Yongping. Analysis of Stability for Pulsating Magnetic Field PM Low Speed Synchronous Motor // S\&M Electric Machines, 2003. - Vol. 30. - P. 21-23.

9. Chandana Perera P. D., Frede B., et.al. A Sensorless, Stable V/f Control Method for Permanent-Magnet Synchronous Motor Drives // IEEE Trans. on Industry Applications, 2003. - Vol. 39. - P. 783-791.

10. Chen Xuezhen, Gu Chenglin. Design research on ALA+SPM rotor synchronous machine // Proceedings of the CSEE, 2010. - Vol. 30. - P. 98-102.

11. Urmoniene L., Gecys S., Guseinoviene E., Cirtautas V. Investigation of Energetic Parameters of Oscillating Synchronous Pulsating Current Motors // Electronics and Electrical Engineering. - Kaunas: Technologija, 2011. - No. 4(110). - P. 17-20.

Received 20101215

Xuezhen Chen, Chenglin Gu. Research on Operating Performance for Hybrid Rotor Synchronous Motor // Electronics and Electrical Engineering. - Kaunas: Technologija, 2011. - No. 7(113). - P. 3-8.

This paper with an open-loop $V / f$ control mode of inverter supply, searched for the causes of the oscillation using small signal analysis on the axially-laminated anisotropic (ALA) rotor and hybrid rotor (ALA-SPM two-part) motor, and analyzed operating performance of the motors with inertial damper on the same shaft. Results show that the negative electromagnet damping coefficient can be the key point to result in the oscillation; the electromagnet damping coefficient can increase with the increasing new variable k, the fraction length of SPM part, the maximum load of the motors and the stability can be improved. The stability of the system and the dynamic performance can be better with reasonable viscous damping coefficient of inertial damper, the motors can adequately develop their output torque capability, and improve operating performance. Ill. 11, bibl. 11, tabl. 3 (in English; abstracts in English and Lithuanian).

Xuezhen Chen, Chenglin Gu. Hibridinio rotorinio variklio darbo našumo tyrimas // Elektronika ir elektrotechnika. - Kaunas: Technologija, 2011. - Nr. 7(113). - P. 3-8.

Analizuojami mažų signalų hibridinio rotorinio variklio, veikiančio atviro ciklo $V / f$ valdymo režimu, virpesiai, tiriamas to paties veleno su inerciniu slopintuvu variklių darbo našumas. Nustatyta, kad neigiamas elektromagnetinis slopinimo koeficientas daugiausia ịtakos turi signalo virpesiams. Elektromagnetinis slopinimo koeficientas didèja didèjant naujam kintamam dydžiui $k$, keičiantis SPM dalies ilgiui. Naudojant inercinio slopintuvo klampiojo slopinimo koeficientą, galima padidinti sistemos stabilumą ir dinaminị našumą. Il. 11, bibl. 11, lent. 3 (anglų kalba; santraukos anglų ir lietuvių k.). 